\title{
Mobile Application for the Grantham Script
}

U.Azhagurajan, D.Sakthivel, R.Ayyappan,

Department of Computer Science,

Annai violet arts and Science College, Email :azhagujai@gmail.com

\section{Abstract:}

Grantham is one of the Indian script which is mostly used in the sixth century and the twentieth century by the southern people especially people who all are speak Tamil and Malayalam. Particularly people in Tamilnadu and Kerala to write Sanskrit and the classical language called Manipravalam. And still the Grantham language is in restricted use in traditional Vedic Schools called vedha patasala. So this document targets towards create a mobile application for this ancient language and this application will help the users to learn this language without the physical guidance. The Grantham script are inserted in the application by using the digital image processor and this application will help the learners to learn Grantham in the Exact way of teaching in vedha patasala. The main focus of this document was to develop the mobile application for the educational purpose for the interested people, and in the future the voice clips also provide for better learning.

Key word: Grantham, Vedha, Patasala

\section{Introduction}

The Grantha script was designed for writing the holly texts in the Sanskrit language. The script is thought to be based on the stone-age cave inscriptions, and to have gone through three stages of development; Early, Middle and Modern[1][2].

There are two main types of Modern Grantha; Eastern Grantha and Tulu-Malayalam.Eastern Grantha was written in the state of Tamil Nadu in two distinct hands; a Brahmanical (Kooteluthu) variety used in Tanjore province, and a Jain (vatteluthu) variety used around Arcot and Chennai.

Tulu-Malayalam writing is still taught and used in Gürūkuls, residential Hindu schools (i.e Veda patasalas ). It preserves some of the older letter forms which were later modified in Eastern varieties of the script. Nowadays the grandham script was its use in the Gūrūkuls community[3][4][5].

There was a third type of the script called Tamil Grantha which was used in the 5th and 6th centuries for writing both Tamil and Sanskrit.

\section{Grantha vowels}

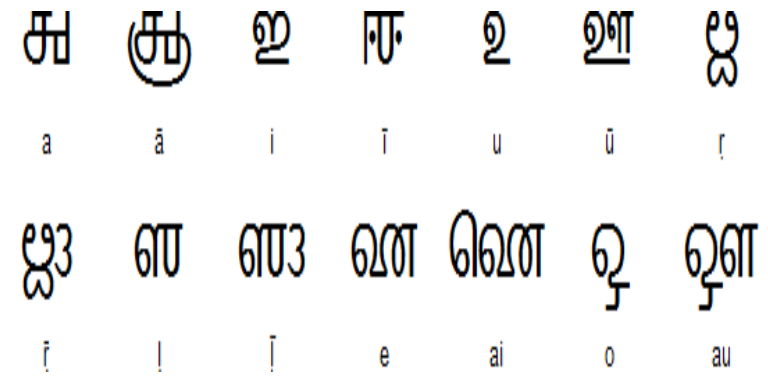

Picture courtesy: Tuticorin Veda patasala

In Each letter represents either a vowel or a consonant+vowel. As like the all languages grandham language also having the vowel and consonant .

\section{Grantha consonants}

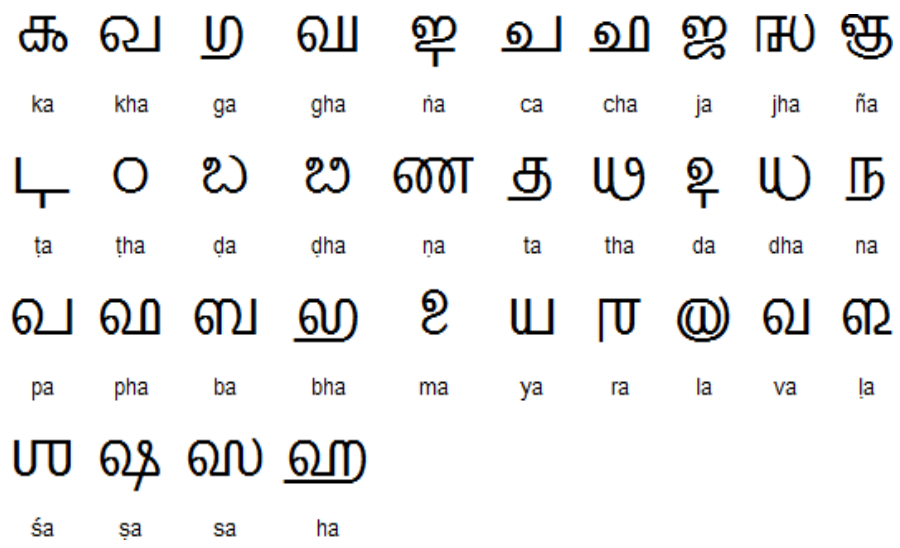

Picture courtesy: Tuticorin Vedha patasala

There are 14 vowel letters and 34 consonant There are also 3 subsidiary consonant letters used for writing consonant clusters containing $y$ or $r$. Thesymbols anusvara (:)and visarga( $Z$ ) were used as in a number of South Asian scripts for representing nasalization and voiceless breath respectively[6][7][8].

The aim of this paper is attempt to develop a mobile application for the grandham script for the needy people. grandham language has the strong connection with the Malayalam. The reorganization of the 
grandham script is quite difficult due to the pronunciations

\section{Concept Of M-Learning}

In this modern world everyone has their own handheld mobile devices with the internet facility. The user can interact with people from anywhere in the world. Without any limitation of time and place. Mobile learning refers to the implementation of mobile devices in any branch of study. The advantages of mobile technology such as the portability and information accessibility play a vital role in the enhancement of language teaching and learning. The main characteristic of M-Learning can be the discretion of the learner.

\section{Classification of Mobile learning App:}

The Mobile learning applications are classified in to three major categories they are

$>$ App for primary learner

$>$ App for secondary learner

$>$ App for tertiary learner

\section{About the Application :}

In this mobile application the aksharas of the grandham are inserted in proper manner. If the user want to learn the grandham means they can easily download the application from the play store. And the application let the user to learn the grandham in the daily basics without any physical guidance .The all aksharas has their equivalent Tamil letters thus the user can easily understand the aksharas of grandham[9][10]. The primary learner can start the course by the balalpadam (i.e. primary level lessons including the alphabets and numeric's ) The secondary learner and the tertiary learners can use this app for next level of their learning those lessons contains the words and the passages. Thus the user can get fluency in the grandham language[11][12].

\section{Conclusion:}

I hope this application will help the users to learn the grandham in the proper way how teach by the patasalas. With the help of this application many user can get the knowledge about the grandham. And with the help of this application the users can read and write the scripts in the grandham without any mistakes. the voice clips may help the user to pronounce the letters with the correct pronunciations. Because the pronunciations play the main role in the grandham if the user mis-pronounces the letter means the alphabet will differ while writing the script. Usually in Vedas the sound is very important while chanting the mantras. so this application will definitely help the user to neglects those errors and get fluency in grandham.

\section{Future Enhancements:}

In the future this application will designed with the voice clips for the each text in the grandham. In starting stage the application have only one equivalent language (Tamil).In future the user can select the language as per their wish (i.e. the equivalent language of the grandham script is decide by the user )Thus many user can learn grandham without any language problem. And the advanced level of this application is the user can get the equivalent sentence of the grandham script by the clicking the grandham script .

\section{Reference:}

1. Sreeraj.M and Sumam Mary IdiculaAn Online Character Recognition System to Convert Grantha Script to Malayalam

2. H.Swethalakshmi, Online Handwritten Character recognition for Devanagari and Tamil Scripts using Support Vector Machines, Master's thesis, Indian Institute of Technology, Madras, India: 2007.

3. http://www.virtualvinodh.com/wp/aksharamukha

4. http://www.virtualvinodh.com/wp/grantha

5. Ramya Gangaiamaran and Madhumathi Pasupathi Review on Use of Mobile Apps for Language Learning

6. Alkhamis, H. I., 2014, "Implementing iPad apps for elementary language arts Students," EWU Masters Thesis Collection. Paper 188

7. Al-Zahrani, A.S., 2015, "Smartphones wandering at the mall: A case study investigating the use of smartphones on English oral learning skills in a collaborative mobile-assisted language learning environment," Ph.D. thesis, Northern Illinois University.

8. Baskar, S., 2013, "How mobile apps influence childhood education," Retrieved from http://edtechreview.in/e-learning/529-mobileappsinfluence-childhood-education

9. Brady, T., 2016, "The Implementation of LanguageImmersion Technology, Kindergarten through Grade 5: A Multiple-Case Study," Northcentral University

10. Beatty, K., 2010, "Teaching and Researching Computer-Assisted Language Learning," Harlow: Pearson/Longman 2nd Ed

11. Sri.Selvaganesapattar,Tuticorin Aalala Sundhara Vedha Siva Aagama Padasalai

12. Sri.Vignesh Sivam, Sivapuram Siva Aagama Padasalai 